\title{
AVALIAÇÃO E OTIMIZAÇÃO DO USO DE LEVEDURAS PROVENIENTES DE UVA PATRÍCIA (VITIS VINIFERA $X$ ) NA PRODUÇÃO DE BEBIDAS FERMENTADAS
}

\author{
Wallisson dos Santos Lima ${ }^{1}$; José Ailton Conceição Bispo ${ }^{2}$; Joelma Souza \\ Oliveira $^{3}$ e Laís Maciel Rodrigues ${ }^{4}$ \\ 1. Bolsista PROBIC/UEFS, Graduando em Engenharia de Alimentos, Universidade Estadual de Feira de Santana, e- \\ mail: wallisson51@hotmail.com \\ 2. Orientador, Departamento de Tecnologia, Universidade Estadual de Feira de Santana, e-mail: \\ bispo.ailton@gmail.com \\ 3. Participante do projeto, Departamento de Tecnologia, Universidade Estadual de Feira de Santana, e-mail: \\ joelmasouzatst@gmail.com \\ 4. Participante do projeto, Departamento de Tecnologia, Universidade Estadual de Feira de Santana, e-mail: \\ sialmaciel@gmail.com
}

PALAVRAS-CHAVE: Fermentação, Monod, Modelagem numérica.

\section{INTRODUÇÃO}

A presente proposta visa obter condições para compor um setor de modelagem matemático-estatístico capaz de aperfeiçoar as condições de produção e ao mesmo tempo diversificar a gama de produtos fermentados provenientes de frutos climatéricos das regiões norte e nordeste. O intuito de gerar novas patentes de produtos e processos aliadas à geração e registro de softwares de caracterização e controle. Neste contexto, a presente pesquisa propõe avaliar a eficiência na produção de bebidas fermentadas à partir da utilização de leveduras provenientes da uva Patrícia (Vitis vinifera $\boldsymbol{x}$ ) utilizando como mosto o suco da própria uva com vistas à produção e caracterização do processo fermentativo de vinhos. Pois a realização de melhorias no desenvolvimento de cervejas e vinhos pelo processo descontínuo utilizando como adjunto frutas do semiárido baiano vêm sendo avaliada há alguns anos com vistas à descoberta de novos produtos e processos.

Desde o desenvolvimento de modelos computacionais em ambiente MatLab destinados à modelagem e otimização de processos biotecnológicos de inativação viral, secagem e cinética enzimática (Bispo et al., 2012. 2013a, 2014, 2015), nosso grupo tem voltado a atenção aos processos fermentativos, visto que, uma das mais importantes linhas de investigação cervejeira da região nordeste encontra-se hoje no NÚCLEO DE INOVAÇÃO EM TECNOLOGIAS DE FERMENTAÇÃO da Universidade Estadual de Feira de Santana (UEFS-Bahia).

\section{METODOLOGIA}

\section{1- Obtenção e Crescimento das leveduras}

As leveduras provenientes da uva foram isoladas a partir de suco mantido sob aeração contínua em banho termostático a $32^{\circ} \mathrm{C}$ e um teor de açúcar $\left({ }^{\circ}\right.$ Brix) em torno 10 . Após esta primeira etapa, foi retirado $0 \%, 10 \%, 20 \%$ e $30 \%$ da solução resultante que foi então diluída em uma solução de cana de açúcar com teor de açúcar de $10 \%$ até o 
volume de $80 \mathrm{~mL}$. Dessa forma, uma vez detectada a presença de leveduras, as mesmas foram então crescidas e isoladas em placas de Petri para posterior identificação e caracterização de uma ou mais espécies.

\section{2-Centrifugação e Liofilização das leveduras}

As leveduras obtidas durante o processo de crescimento foram então centrifugadas a $6000 \mathrm{rpm}$ e uma vez descartado o sobrenadante as mesmas foram liofilizadas durante 8 horas para remoção da água livre para posterior armazenamento em freezer. Embora não fizesse parte do plano de trabalho, este liofilizador foi construído nesse período por nosso grupo.

\section{3- Análise da Atividade Fermentativa:}

O andamento do processo fermentativo foi monitorado no decorrer do tempo em relação à concentração inicial de inóculo, por meio da produção de etanol determinada através de densímetro digital e grau de fermentação. A concentração inicial de açúcares dissolvidos será de $8,12,14,18,22$ e $26^{\circ}$ Brix para uma variação no inóculo inicial de $5,10,15,25,30$ e $50 \% \mathrm{v} / \mathrm{v}$. Todos os reagentes utilizados foram da grade analítica.

\section{RESULTADOS E/OU DISCUSSÃO}

Inicialmente as leveduras passaram por um processo de crescimento, envolvendo a presença de nutrientes e contando com uma aeração constante com ar filtrado por meio de filtros Hepa. Nesse processo, cria-se um ambiente propicio para a propagação das leveduras até concentrações propícias a fermentação alcoólica necessária para produção de cerveja assim como a produção de licores. Em seguida, depois da fermentação, verificou-se a capacidade de produção de etanol por cada cepa de levedura.

Abaixo apresentam demonstrados nas figuras 1, 2 e 3 os valores experimentais obtidos nas analises.

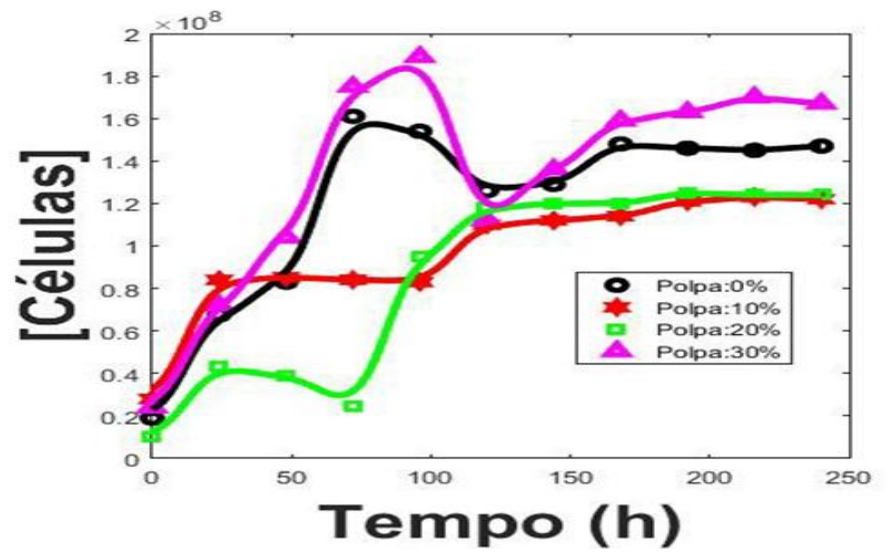

Figura 1

A Figura 1 apresenta os resultados para o crescimento celular durante o processo fermentativo (símbolos) e os seus respectivos ajustes do processo de modelagem (linha). Durante esse processo observou-se uma alta aderência do modelo com valores de R2>0.9 e uma distribuição randômica dos resíduos. 
Assim, a partir dessa figura pode-se observar que as maiores quantidades de células em solução foram observadas para concentrações de polpa em torno de $30 \%$ e tempos de fermentação compreendidos entre 50 e 150 200 horas.

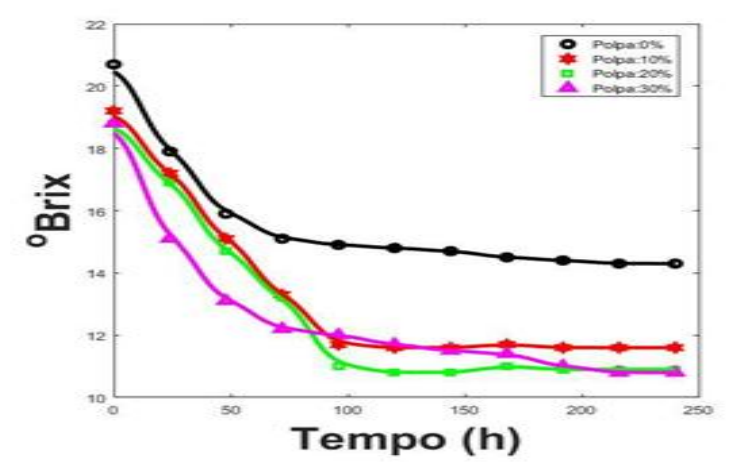

Figura 2

Observando a Figura 2 observa-se ainda que para 20 e $30 \%$ de polpa a velocidade de consumo de substrato é alta e muito parecida para tempos inferiores a 100 horas. Esses resultados podem ainda ser melhor observados a partir das Figuras 5 e 6 a seguir.

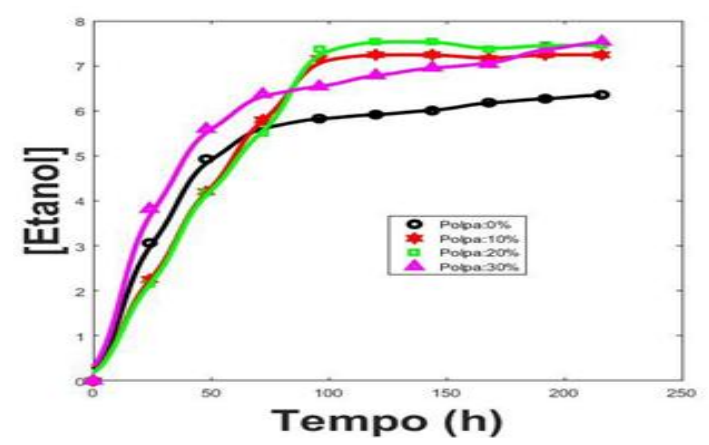

Figura 3

Dessa forma pode-se concluir com a figura 3 que as maiores velocidades de produção de etanol para esse processo ocorrem a tempos de fermentação inferiores a 50 horas e que esse processo poderia ser interrompido após 150 horas uma vez que a produção de etanol atingiria patamares aproximadamente constantes. Economizando assim tempo e aumentando a produtividade.

\section{CONSIDERAÇÕES FINAIS}

Apesar das dificuldades e constantes perda de material biológico e de bateladas de fermentação por cota das paralisações, os resultados foram muito satisfatórios e apresentam grande potencial para o desenvolvimento de novos processos. Além de gerarem informações imprescindíveis para futuras otimizações.

\section{REFERÊNCIAS}


Bispo, J. A. C., Bonafe, C. F. S., Koblitz, M. G. B., Silva, C. G. S., \& Souza, A. R. (2013a). Substrate and enzyme concentration dependence of the Henri-MichaelisMenten model probed by numerical simulation. Journal of Mathematical Chemistry, $51(1), 144-152$.

Bispo, J. A. C. et al. (2014). Applying structural transition theory to describe enzyme kinetics in heterogeneous systems. J. Mathematical Chemistry.

Bispo et al. (2015). A comparison of drying kinetics based on the degree of hydration and moisture ratio. LWT Food Science and Technology.

Bispo et al. (2014). Optimizing Drying Processes Using a structural Transition Model and Entropy Change Maximization. Drying Technology

Bispo, J. A. C., Silva, C. M. R., Bonafe, C. F. S., \& Assis, D. J. (2013b). Modeling drying isotherms using a structure transition model. Drying Technology, in press.

Bispo, J. A. C., Bonafe, C. F. S., Joekes, I., Martinez, E. A., Carvalho, G. B. M., \& Norberto, D. R. (2012). Entropy and volume change of dissociation in tobacco mosaic virus probed by high pressure. Journal of Physical Chemistry B, 166(51), 1481714828.

Bispo, J. A. C., Bonafe, C. F. S., de Souza, V. B., Silva, J. B. A., \& Carvalho, G. B. M. (2011). Extending the kinetic solution of the classic Michaelis-Menten model of enzyme action. Journal of Mathematical Chemistry, 49(9), 1976-1995.

CARVAlHO, G. B. M., ROSSI, A. A., ALMEIDA E SILVA, J. B. Elementos Biotecnológicos Fundamentais no Processo Cervejeiro: $2^{\circ}$ Parte - A Fermentação. Revista Analytica, n 26, p 46-54, 2007. 